\title{
Bactrian ("Double Hump") Acetaminophen Pharmacokinetics: A Case Series and Review of the Literature
}

\author{
Robert G. Hendrickson • Nathanael J. McKeown • \\ Patrick L. West • Christopher R. Burke
}

Published online: 6 May 2010

(C) American College of Medical Toxicology 2010

\begin{abstract}
After acute ingestion, acetaminophen (APAP) is generally absorbed within $4 \mathrm{~h}$ and the APAP concentration ([APAP]) slowly decreases with a predictable half-life. Alterations in these pharmacokinetic principles have been rarely reported. We report here three cases of an unusual double hump, or Bactrian, pattern of [APAP]. We review the literature to describe the case characteristics of these rare cases. A 38-year-old woman ingested 2 g hydrocodone $/ 65 \mathrm{~g}$ acetaminophen. Her [APAP] peaked at $289 \mathrm{mcg} / \mathrm{mL}(8 \mathrm{~h})$, decreased to $167 \mathrm{mcg} / \mathrm{mL}(31 \mathrm{~h})$, then increased to $240 \mathrm{mcg} / \mathrm{mL}(39 \mathrm{~h})$. She developed liver injury (peak AST 1603 IU/L; INR1.6). A 25-year-old man ingested $2 \mathrm{~g}$ diphenhydramine/26 g APAP. His [APAP] peaked at $211 \mathrm{mcg} / \mathrm{mL}(15 \mathrm{~h})$, decreased to $185 \mathrm{mcg} / \mathrm{mL}$
\end{abstract}

\section{Funding None}

Previous Presentations Presented at the North American Congress of Clinical Toxicology, San Antonio, TX, 2009.

R. G. Hendrickson · N. J. McKeown · P. L. West

Oregon Poison Center,

Portland, OR, USA

R. G. Hendrickson • N. J. McKeown • P. L. West • C. R. Burke Oregon Health and Science University,

Portland, OR, USA

N. J. McKeown

Portland Veteran's Affairs Medical Center,

Portland, OR, USA

C. R. Burke

University of Sydney,

Sydney, NSW, Australia

R. G. Hendrickson $(\bowtie)$

3181 SW Sam Jackson Park Road, CSB 550,

Portland, OR 97210, USA

e-mail: hendriro@ohsu.edu
$(20 \mathrm{~h})$, and increased again to $313 \mathrm{mcg} / \mathrm{mL}(37 \mathrm{~h})$. He developed liver injury (peak AST 1153; INR 2.1). A 16-year-old boy ingested $5 \mathrm{~g}$ diphenhydramine and $100 \mathrm{~g}$ APAP. His [APAP] peaked at $470 \mathrm{mcg} / \mathrm{mL}(25 \mathrm{~h})$, decreased to $313 \mathrm{mcg} / \mathrm{mL}(36 \mathrm{~h})$, then increased to $354 \mathrm{mcg} / \mathrm{mL}$ (42 h). He developed liver injury (peak AST $8,686 \mathrm{IU} / \mathrm{L}$; peak INR 5.9). We report three cases of Bactrian ("double hump") pharmacokinetics after massive APAP overdoses. Cases with double hump pharmacokinetics may be associated with large ingestions (26-100 g APAP) and are often coingested with antimuscarinics or opioids. Several factors may contribute to these altered kinetics including the insolubility of acetaminophen, APAP-induced delays in gastric emptying, opioid or antimuscarinic effects, or enterohepatic circulation. Patients with double hump APAP concentrations may be at risk for liver injury, with AST elevations and peaks occurring later than what is typical for acute APAP overdoses.

Keywords Acetaminophen - Toxicity Pharmacokinetics . Bactrian · Overdose

\section{Introduction}

The pharmacokinetics of acetaminophen after acute overdose has been well described $[1,2]$. Typically, acetaminophen is completely absorbed and peak serum concentrations occur within $4 \mathrm{~h}$ of ingestion. Acetaminophen concentrations quickly drop from this initial peak with a half-life of $2-4 \mathrm{~h}[1,2]$. The modified Rumack-Matthew nomogram is used to determine treatment for patients with acute acetaminophen ingestions and was based on these pharmacokinetic principles [3, 4].

Exceptions to these typical pharmacokinetics have rarely been reported including delayed absorption associated with 
coingestants that slow gastric emptying or gastrointestinal peristalsis [5-9]. We report here three cases where the acetaminophen concentration peaked, then declined, only to be followed by a subsequent unexpected increase in acetaminophen concentration to a second peak. The etiology of these altered pharmacokinetics and the implications for therapy of these double peaks is unknown.

\section{Case Reports}

Case 1

A 38-year-old female presented to an Emergency Department (ED) approximately $2 \mathrm{~h}$ after ingesting 200 tablets of hydrocodone/acetaminophen (Vicodin ${ }^{\circledR}$ 10/325; 2 g hydrocodone, $65 \mathrm{~g}$ acetaminophen). She denied any other coingestion.

On presentation to the ED, she was awake, alert, and oriented. Her presenting vital signs were: blood pressure $170 / 48 \mathrm{mmHg}$, temperature $36.7^{\circ} \mathrm{C}$, heart rate $67 \mathrm{bpm}$, respiratory rate $16 / \mathrm{min}$, and oxygen saturation $100 \%$ on room air. Her physical examination revealed pupils that were $2 \mathrm{~mm}$ and reactive bilaterally, moist mucous membranes, a regular cardiac rate and rhythm without murmurs, and a benign abdominal examination with normal bowel sounds. Opiates and benzodiazepines were detected by urine immunoassay, while ethanol, amphetamines, barbiturates, cannabinoids, and cocaine were undetectable.

Gastrointestinal decontamination was not performed. Laboratory studies are noted in Table 1. Initial (approximately $2 \mathrm{~h}$ postingestion) acetaminophen concentration was $282 \mathrm{mcg} / \mathrm{mL}$, salicylate $<3 \mathrm{mg} / \mathrm{dL}$, and ethanol $<10 \mathrm{mg} / \mathrm{dL}$. The patient was started on intravenous (IV) Nacetylcysteine (NAC) $4 \mathrm{~h}$ after ingestion and admitted to the hospital with one-to-one observation by a sitter. Repeat (approximately $8 \mathrm{~h}$ postingestion) acetaminophen concentration was $289 \mathrm{mcg} / \mathrm{mL}$. Serial acetaminophen concentrations, transaminases, and INRs are shown over the course of her hospital stay (Table 1).

After $21 \mathrm{~h}$ of treatment with IV NAC $(150 \mathrm{mg} / \mathrm{kg} / \mathrm{h} \times 41 \mathrm{~h}$, $12.5 \mathrm{mg} / \mathrm{kg} / \mathrm{h} \times 4 \mathrm{~h}$, then $6.25 \mathrm{mg} / \mathrm{kg} / \mathrm{h} \times 416 \mathrm{~h}$ ), and contrary to poison center advice, NAC was discontinued for $3.5 \mathrm{~h}$, and then an infusion was restarted at $6.25 \mathrm{mg} / \mathrm{kg} / \mathrm{h}$ without a bolus. The repeat acetaminophen concentration was $167 \mathrm{mcg} / \mathrm{mL}$
(31 $\mathrm{h}$ after ingestion). The acetaminophen concentration subsequently increased to $240 \mathrm{mcg} / \mathrm{mL}$ ( $39 \mathrm{~h}$ after ingestion), then decreased to $142 \mathrm{mcg} / \mathrm{mL}$ ( $43 \mathrm{~h}$ after ingestion), and continued to decline to $<5 \mathrm{mcg} / \mathrm{mL}(73 \mathrm{~h})$. The patient remained on one-to-one observation with a sitter during her entire hospital stay.

Approximately $44 \mathrm{~h}$ after ingestion, an abdominal/pelvic CT scan without contrast was obtained, which did not detect the presence of pills in her gastrointestinal tract. The patient remained on IV NAC and her transaminases and INR peaked $97 \mathrm{~h}$ after ingestion. IV NAC was discontinued $111 \mathrm{~h}$ after ingestion, and she was discharged on day 8 .

Evaluation of other causes of hepatic failure included negative tests for hepatitis A IgM Ab, hepatitis B surface $\mathrm{Ag}$, hepatitis B core IgM, hepatitis C Ab, ceruloplasmin, immunology screen (anti-dsDNA, anti-ssDNA, anti-ENA, anti-SSA [ro], anti-SSB [la], IgA, IgG, IgM), and mitochondrial M2 Ab IgG.

\section{Case 2}

A 25-year-old woman arrived to an ED approximately $2 \mathrm{~h}$ after ingesting 80 tablets of a combination acetaminophen/ diphenhydramine product (Tylenol PM ${ }^{\circledR} ; 26 \mathrm{~g}$ acetaminophen and $2 \mathrm{~g}$ diphenhydramine). On arrival, she appeared intoxicated and was tachycardic at $143 \mathrm{bpm}$ with a blood pressure of $124 / 82 \mathrm{mmHg}$, temperature of $37.6^{\circ} \mathrm{C}$, respirations $22 / \mathrm{min}$, and oxygen saturation of $100 \%$ on $2 \mathrm{~L}$ by nasal cannula. Her physical examination on arrival was significant for reactive pupils and cool dry skin. She had normal cardiac rate and rhythm, clear lung sounds, and an abdomen that was nontender with normal bowel sounds.

Laboratory values are listed in Table 2. Her initial acetaminophen concentration was $164 \mathrm{mcg} / \mathrm{mL}(2 \mathrm{~h}$ after ingestion), serum ethanol was $148 \mathrm{mg} / \mathrm{dL}$, and she was started on IV NAC $(150 \mathrm{mg} / \mathrm{kg} / \mathrm{h} \times 1 \mathrm{~h}, 12.5 \mathrm{mg} / \mathrm{kg} / \mathrm{h} \times 4 \mathrm{~h}$, then $6.25 \mathrm{mg} / \mathrm{kg} / \mathrm{h} \times 16 \mathrm{~h}$ ) approximately $4 \mathrm{~h}$ after her ingestion. Her tachycardia resolved over several hours. Her acetaminophen concentration initially peaked at $211 \mathrm{mcg} / \mathrm{mL}$ (15 h after ingestion). She developed mild antimuscarinic symptoms (i.e., mydriasis and mild agitation). Her acetaminophen concentration then dropped to $185 \mathrm{mcg} / \mathrm{mL}(20 \mathrm{~h}$ after ingestion), only to rebound to $313 \mathrm{mcg} / \mathrm{mL}$ ( $37 \mathrm{~h}$ after ingestion). NAC therapy never lapsed during her care. Her

Table 1 Case 1 laboratory values

\begin{tabular}{lcccccccrrrrrr}
\hline Postingestion (h) & 2 & 8 & 15 & 31 & 39 & 43 & 59 & 73 & 87 & 97 & 111 & 135 & 158 \\
\hline APAP (mcg/mL) & 282 & 289 & 261 & 167 & 240 & 142 & 15 & $<5$ & $<5$ & $<5$ & $<5$ & $<5$ \\
AST (IU/L) & 12 & & & 34 & 67 & & 119 & 491 & 1409 & 1,603 & 608 & 144 & 82 \\
ALT (IU/L) & 10 & & & 35 & 83 & & 185 & 576 & 1765 & 2,351 & 1,672 & 988 & 683 \\
INR & 1.1 & & & & 1.5 & & 1.5 & & & 1.6 & 1.4 & 1.2 & 1.0 \\
\hline
\end{tabular}


Table 2 Case 2 laboratory values

\begin{tabular}{|c|c|c|c|c|c|c|c|c|c|c|c|c|c|c|c|}
\hline Postingestion (h) & 2 & 5 & 9 & 15 & 20 & 26 & 37 & 45 & 61 & 85 & 109 & 133 & 157 & 181 & 229 \\
\hline APAP (mcg/mL) & 164 & 172 & 191 & 211 & 185 & 192 & 313 & 281 & 76 & 13 & & $<5$ & $<5$ & $<5$ & \\
\hline AST (IU/L) & 45 & 31 & & 37 & & 124 & 444 & 571 & 798 & & 1,153 & 415 & 166 & 81 & 42 \\
\hline ALT (IU/L) & 22 & 17 & & 18 & & 82 & & 311 & & & 2,236 & 1,528 & 981 & 692 & 402 \\
\hline INR & & & & & & & 1.4 & 2.1 & 1.3 & 2.1 & 1.3 & 1.1 & & & \\
\hline
\end{tabular}

AST peaked at 1,153 IU/L and ALT peaked at 2,236 IU/L $109 \mathrm{~h}$ after her admission.

Case 3

A 16-year-old boy stated that he ingested 200 tablets of acetaminophen/diphenhydramine (Tylenol $\mathrm{PM}^{\circledR} ; 100 \mathrm{~g}$ acetaminophen and $5 \mathrm{~g}$ diphenhydramine), approximately $1.5 \mathrm{~h}$ prior to arrival. This timing was confirmed by his parent. On arrival, his vital signs were significant for tachycardia, $125 \mathrm{bpm}$, with normal temperature, $36.8^{\circ} \mathrm{C}$, and blood pressure, 130/70 $\mathrm{mmHg}$. He was awake and alert but confused. His pupils were $3 \mathrm{~mm}$ and reactive bilaterally, and he had normal bowel sounds. The remainder of his physical exam was unremarkable.

His initial acetaminophen concentration was $225 \mathrm{mcg} / \mathrm{mL}$ $2 \mathrm{~h}$ after his ingestion. He was treated with an initial $50 \mathrm{~g}$ dose of activated charcoal and started on IV NAC $(150 \mathrm{mg} / \mathrm{kg} / \mathrm{h} \times$ $1 \mathrm{~h}, 12.5 \mathrm{mg} / \mathrm{kg} / \mathrm{h} \times 4 \mathrm{~h}$, then $6.25 \mathrm{mg} / \mathrm{kg} / \mathrm{h} \times 16 \mathrm{~h}$ ) $4 \mathrm{~h}$ after his ingestion. He was transferred to an academic pediatric hospital where he became increasingly somnolent and was intubated. His $5.5-\mathrm{h}$ acetaminophen concentration was $418 \mathrm{mcg} / \mathrm{mL}$ and salicylate concentration $<4 \mathrm{mg} / \mathrm{dL}$. The urine immunoassay did not detect amphetamine, barbiturates, benzodiazepines, cannabinoids, cocaine, or opiates. Whole bowel irrigation with polyethylene glycol was initiated, but was discontinued due to loss of bowel sounds. He received several $1 \mathrm{mg}$ doses of physostigmine with improvement in mental status.

Laboratory values are displayed in Table 3. His acetaminophen concentration peaked at $25 \mathrm{~h}$ after ingestion at $470 \mathrm{mcg} / \mathrm{mL}$, decreased to $313 \mathrm{mcg} / \mathrm{mL}$ at $36 \mathrm{~h}$, then increased again at $42 \mathrm{~h}$ to $354 \mathrm{mcg} / \mathrm{mL}$, and then slowly declined until it became undetectable $(<10 \mathrm{ug} / \mathrm{mL}) 109 \mathrm{~h}$ after ingestion. INR peaked at 5.9 at $79 \mathrm{~h}$ and AST peaked at $8,686 \mathrm{IU} / \mathrm{L} 91 \mathrm{~h}$ after ingestion.

\section{Discussion}

In most acute acetaminophen overdoses, the drug is predictably absorbed from the gastrointestinal tract, reaches peak concentrations within $2-4 \mathrm{~h}$, followed by a rapid decrease in serum concentration with distribution and hepatic metabolism [1,2]. In rare circumstances, significant alterations of these pharmacokinetics characteristics have been reported [5-9].

We report three cases of delayed acetaminophen peak and double hump pharmacokinetics (initial peaks 8,15 , and $25 \mathrm{~h}$ after ingestion and second peak 39,37 , and $42 \mathrm{~h}$ after ingestion). Nine additional cases of double hump pharmacokinetics have been reported previously [10-17]. The characteristics of all 12 cases of double peak acetaminophen concentrations are summarized in Table 4.

Analysis of these double peak acetaminophen cases reveal that there are several commonalities among the cases that are unusual in acute acetaminophen overdoses. First, all of the overdoses were large oral ingestions (26-100 g). Second, most of the overdoses had coingestions of an antimuscarinic or opioid medication, both of which may decrease gastric emptying [18]. Third, it seems that liver injury is common in patients with a second peak who are reported in the literature. Whether this is due to publication bias or due to the amount ingested or altered pharmacokinetics is not known.

\section{Possible Etiologies of Altered Kinetics}

The etiology of the altered kinetics of acetaminophen in these cases is unclear. Several theoretical causes exist and may, individually or in some combination, explain this double hump phenomenon. These mechanisms reflect some manner of delay in absorption of acetaminophen from the gastrointestinal tract and include decreased gastric emptying, decreased solubility of tablets, and/or pharmacobezoar formation.

In all three of our cases, as well as five other reported cases $[10,12-15]$, a coingestion of an antimuscarinic or opioids was reported or suspected. In one case, a coingestant was not reported [14].

Interestingly, there are four described cases of patients who developed double peaks after acute acetaminophen overdose where there are no reported or recognized coingestions (Table 4). Smith et al. recently presented a case of a double peak acetaminophen concentration in which no coingestants were reported [11]. In this case, the patient ingested $48 \mathrm{~g}$ of acetaminophen and developed an acetaminophen concentration peak at $6 \mathrm{~h}$, nadir at $27 \mathrm{~h}$, and second peak at $48 \mathrm{~h}$. Urine immunoassay did not detect opioids, including 


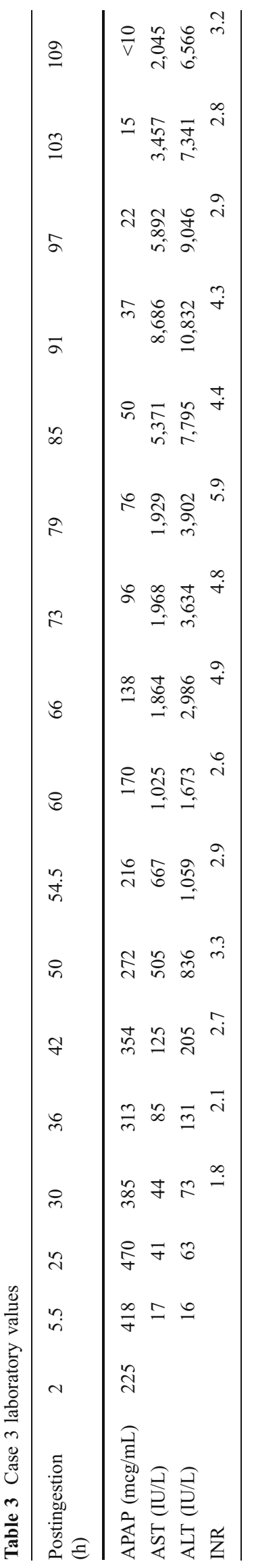

methadone or propoxyphene, but no further comprehensive testing for coingestions was performed.

Kobrinsky et al. reported a prospective trial of 78 therapeutic massive (up to $1 \mathrm{~g} / \mathrm{kg}$ ) acetaminophen ingestions followed by NAC rescue at $8 \mathrm{~h}$ for the treatment of a variety of cancers [16]. In this trial, 3 of 78 (4\%) patients developed a double peak in acetaminophen concentration. Unfortunately, no specific details were provided for any of these cases and all case data has since been destroyed. No liver injury was reported in any of the study patients. The authors state that some patients in the study may have been therapeutically taking chronic opioids that might alter gut motility, but as these were patients in a prospective chemotherapeutic trial, it is evident that these patients did not coingest other medications in overdose quantities.

There remains some controversy as to whether opioids or antimuscarinics significantly affect absorption. In scintigraphy studies, gastric emptying half-time is more than doubled by opioids and antimuscarinic agents [18]. In volunteer studies of subtoxic but supratherapeutic acute acetaminophen ingestions, peak acetaminophen concentrations are delayed with oxycodone ingestion, but not with diphenhydramine [19]. In overdose patients, calculated 4-h acetaminophen concentrations for patients with opioid/acetaminophen overdoses were not significantly different from those who reported similar amounts of ingested acetaminophen alone [20]. Together, these studies suggest a delay in gastric emptying with coingestion of an opioid or antimuscarinic, but without a clearly defined impact on early serum acetaminophen concentrations. Unfortunately, no comprehensive prospective study on overdose patients has been performed to determine the rate of absorption, peak time of acetaminophen concentration, or clinical effects of any delayed absorption.

Several other factors may play a role in prolonging gastric emptying in patients who ingest acetaminophen. Stress, fear, and pain may decrease gastric emptying and are often present after overdose [18]. In addition, the simple presence of a large number of acetaminophen tablets in the stomach doubles the gastric emptying half-life in overdose patients [18]. This effect may explain the altered kinetics in the Kobrinsky and Smith cases where there may be no pharmacologic reason for delayed absorption [11, 16]. However, a threshold amount of acetaminophen tablets for this effect is not currently known.

Another possible etiology for the altered kinetics is that acetaminophen formed a pharmacobezoar resulting in the delayed acetaminophen peak. Though described in several other medication overdoses, pharmacobezoars have not been previously described with acetaminophen products [21-23]. In our first case, radiological imaging did not detect a pharmacobezoar.

Yet another potential etiology was detailed by Smith and suggests that double peaks or delayed absorption may be 


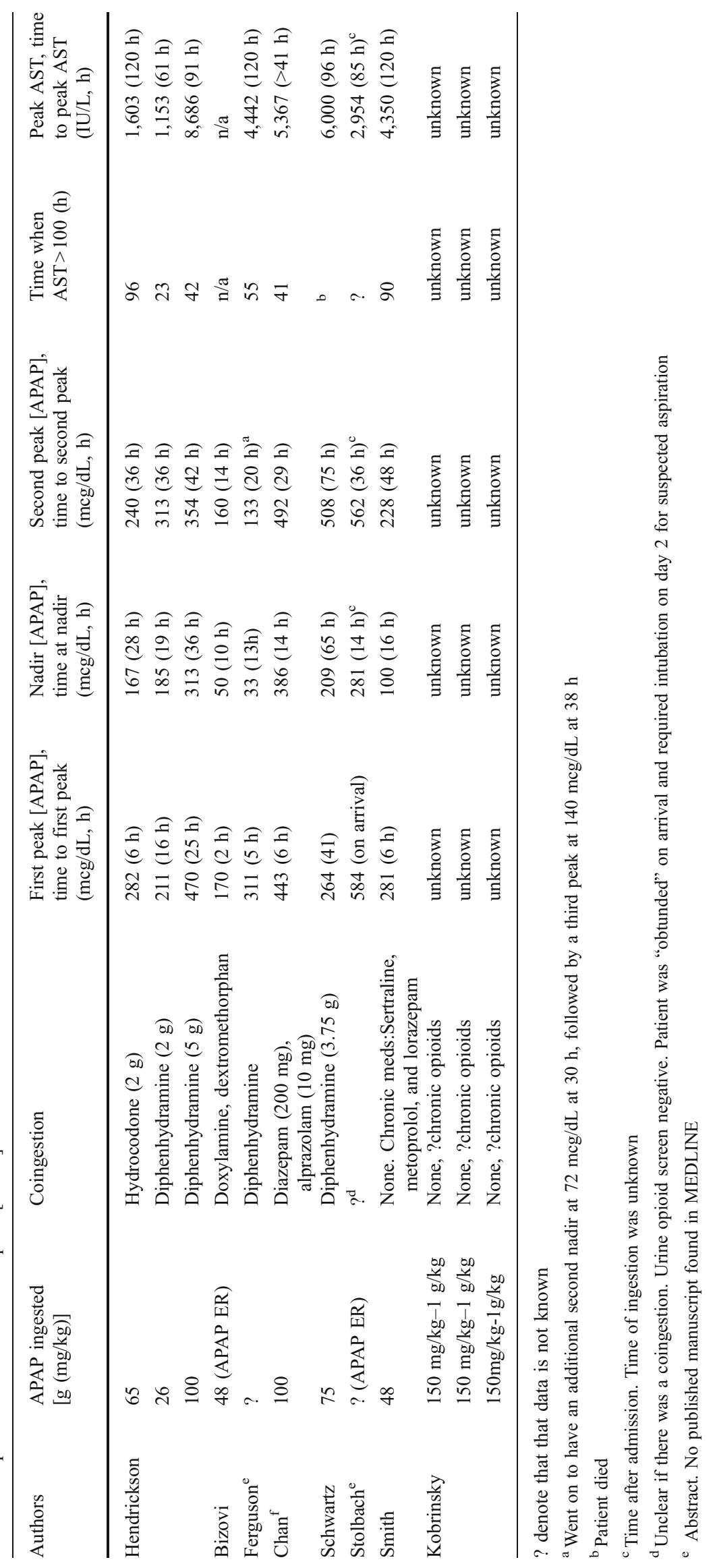


due to the poor water solubility of acetaminophen $(1.1 \mathrm{~g}$ acetaminophen $/ 100 \mathrm{~mL}$ of water at $25^{\circ} \mathrm{C}$, with slightly higher solubility at higher temperatures, e.g., $\left.37^{\circ} \mathrm{C}\right)[11]$. Given this solubility, the amount of gastric fluid needed to dissolve $100 \mathrm{~g}$ of acetaminophen (as was ingested in our third case) is approximately $9 \mathrm{~L}$ which is likely beyond the capacity of the stomach. It is possible that this explains the correlation between the double peak phenomena and massive ingestions $(>26 \mathrm{~g})$.

Enterohepatic circulation has also been suggested as a reason for the double peak phenomena in addition to prolonging the apparent half-life [24]. While no studies have been performed in humans, animal studies have shown a dose-dependent increase in biliary excretion of acetaminophen as well as the biliary secretion of the glucuronide conjugate which was converted back to parent drug by hydrolysis by intestinal gut flora $[25,26]$. In addition, oral doses of both activated charcoal and cholestyramine decrease acetaminophen concentration and half-life and increase urinary excretion after IV administration of acetaminophen [25, 27].

\section{Liver Injury in Patients with Double Hump Kinetics}

Liver injury does appear to be a prominent feature of the double peak phenomenon. Perhaps this should not be surprising given that these are massive overdoses. However, all three of our cases were treated with IV NAC within $6 \mathrm{~h}$ of reported ingestion, and our third case was treated within $4 \mathrm{~h}$ of a witnessed ingestion. The onset of AST concentration increase appeared to be somewhat delayed. In our cases, the AST increased above $100 \mathrm{IU} / \mathrm{L}$ at 26, 42, and $59 \mathrm{~h}$ after ingestion and crossed $1,000 \mathrm{IU} / \mathrm{L}$ at 60,87 , and 109 h. For comparison, in one prospective study, $75 \%$ of patients developed AST elevations within $24 \mathrm{~h}$ and all developed AST elevation by $36 \mathrm{~h}$ [28]. Other double hump cases in the literature also note delayed initial AST elevation (>100 IU/L) at 41, 55, and $90 \mathrm{~h}$ (Table 4) [11-13].

One concerning factor in our first case was the inappropriate cessation of NAC after the standard $21 \mathrm{~h}$ protocol. In this case, and two others in the literature [11, 12] with double hump kinetics who were treated with a 21-h protocol, subsequent liver injury was observed. In all three cases, NAC was stopped after the standard 21-h protocol while the acetaminophen concentration remained highly elevated $(>100 \mathrm{mcg} / \mathrm{mL}$; Table 5$)$; NAC was restarted after a delay and the patient developed delayed onset of liver injury (i.e., AST $>1,000 \mathrm{IU} / \mathrm{L} ; 55$, 87 , and $96 \mathrm{~h}$ ). These cases highlight the need to carefully reassess patients prior to cessation of NAC. As our other two cases demonstrate, however, even with prolonged continuous infusion of NAC, delayed hepatotoxicity may be seen.
Table 5 Acetaminophen concentrations and AST values when Nacetylcysteine infusions were stopped in cases of liver injury

\begin{tabular}{lccc}
\hline Authors & $\begin{array}{l}\text { [APAP] at time } \\
\text { that NAC was } \\
\text { discontinued }\end{array}$ & $\begin{array}{l}\text { AST at time } \\
\text { that NAC was } \\
\text { discontinued }\end{array}$ & $\begin{array}{l}\text { AST at time } \\
\text { that NAC was } \\
\text { reinstated }\end{array}$ \\
\hline Ferguson. et al. & $133 \mathrm{mcg} / \mathrm{mL}$ & $?$ & 395 \\
Hendrickson. et al. & $167 \mathrm{mcg} / \mathrm{mL}$ & 34 & $\sim 67$ \\
Smith. et al. & $116 \mathrm{mcg} / \mathrm{mL}$ & $<50$ & 395 \\
\hline
\end{tabular}

? denote that that data is not known

Treatment Considerations and Controversies

These cases are clearly rare and seem to occur in select cases with coingestion of opioids and/or antimuscarinics or in cases of massive acetaminophen ingestion. Given that they have a high risk for liver injury, it may be reasonable to assess previous assumptions about acetaminophen and whether there are prediction factors that might change management.

First, given that there is evidence for delays in gastric emptying with acetaminophen overdoses, is it reasonable to treat patients with oral activated charcoal (AC) after the first 1-2 $\mathrm{h}$ after an acute massive ingestion of acetaminophen? There are several reasons to consider that acetaminophen may remain in the stomach in these unusual cases and contribute to the late absorption; low solubility of acetaminophen [11] and decrease in gastric emptying after massive doses of acetaminophen [18]. Indeed, there is some evidence that late treatment of acetaminophen ingestions (up to $12 \mathrm{~h}$ postingestion) with charcoal may be beneficial [29]. Whether this benefit is due to delayed gastric emptying or interruption of enterohepatic circulation is not clear. A prospective evaluation of patients with either massive ingestions or significant coingestants may clarify whether late $(>2 \mathrm{~h}$ after ingestion) charcoal may be effective.

Dose is another consideration in AC therapy. Activated charcoal binds optimally to medications when provided in a 10:1 activated charcoal (AC) to drug ratio or greater [30]. In cases of massive ingestion, the amount of $\mathrm{AC}$ given is not capable of binding all of the acetaminophen in the stomach. It may be a reasonable approach in massive ingestions or ingestions with significant coingestants that the AC dose be repeated as with multidose activated charcoal regimens (50 g AC PO q 2-4 h). Again, a prospective evaluation would help to clarify this question.

As stated above, one of our cases and two previously reported cases [11, 12] of double hump pharmacokinetics have been associated with premature NAC discontinuation. We are unable to correlate discontinuation of NAC with acetaminophen pharmacokinetics; however, these cases of altered pharmacokinetics likely represent massive ingestions 
with a high likelihood of persistent acetaminophen concentration at the completion of a standard 21-h intravenous infusion of NAC (Table 4). For this reason, it must be stated again, once NAC is initiated, it should be given for the duration of the protocol chosen. When nearing the end of the NAC protocol, NAC should be continued if the patient has (1) evidence of liver failure (e.g., encephalopathy, coagulopathy), (2) remaining acetaminophen in the serum, or (3) elevations of the transaminases [17].

Finally, our third case developed liver injury and coagulopathy despite early and continuous IV NAC therapy. The patient had IV NAC bolused within $4 \mathrm{~h}$ after ingestion and had continuous IV NAC, yet developed a peak INR of 5.9. It is difficult to determine if an increased or altered NAC dose would change outcomes or if the oral dosing protocol, which provides larger amounts of NAC, would be more effective in these patients. Prospective studies on alternative NAC dosing may be able to determine if additional NAC is necessary in cases of massive ingestion or altered kinetics.

\section{Conclusions}

We describe three patients with large ingestions of acetaminophen combined with hydrocodone or diphenhydramine who had significantly altered pharmacokinetics including a double peak of their serum acetaminophen concentration, delayed peaks in acetaminophen concentration, and with development of liver injury 60,87 , and $109 \mathrm{~h}$ after ingestion.

It is important for clinicians to be aware that acetaminophen pharmacokinetics may not be predictable in massive overdose and that altered pharmacokinetics may occur, not only when coingested with an antimuscarinic or opioid, but also in cases of isolated APAP overdose. Clinicians should be aware that these overdose patients are at risk for this double peak phenomenon, and at significant risk for liver injury from these overdoses if not treated appropriately and thoroughly. Further, it is important to understand that treatment with NAC involves two decisions, when to initiate NAC and when to discontinue NAC [31]. Under all circumstances, patients with massive ingestions of acetaminophen should be evaluated with an acetaminophen concentration and an AST concentration prior to discontinuation of NAC, regardless of the protocol instituted [17, 31]. If either the AST or acetaminophen concentrations are abnormal, the NAC should be continued at a steady state.

\section{References}

1. Ameer B, Divoll M, Abernethy DR, Greenblatt DJ, Shargel L (1983) Absolute and relative bioavailability of oral acetaminophen preparations. J Pharm Sci 72(8):955-958
2. Divoll M, Abernethy DR, Ameer B, Greenblatt DJ (1982) Acetaminophen kinetics in the elderly. Clin Pharmacol Ther 31 (2):151-156

3. Smilkstein MJ, Knapp GL, Kulig GL et al (1988) Efficacy of oral $\mathrm{N}$-acetylcysteine in the treatment of acetaminophen overdose. $\mathrm{N}$ Engl J Med 319:1557-1562

4. Rumack BH (2002) Acetaminophen hepatotoxicity: the first 35 years. J Toxicol Clin Toxicol 40:3-20

5. Tighe TV, Walter FG (1994) Delayed toxic acetaminophen level after initial four hour nontoxic level. Clin Toxicol 32(4):431-434

6. Gesell LB, Stephan M (1996) Delayed acetaminophen peak and toxicity in combination products [abstract]. J Toxicol Clin Toxicol 34:568

7. Caraccio TR, Mofenson HC, Lawless MJ (1997) Delayed peak acetaminophen (APAP) levels [abstract]. J Toxicol Clin Toxicol 35:563

8. Ho SY, Arellano M, Zolkowski-Wynne J (1999) Delayed increase in acetaminophen concentration after Tylenol PM overdose. Amer J Emerg Med 17(3):315-317

9. Spiller HA (2001) Persistently elevated acetaminophen concentrations for two days after initial four hour non-toxic concentration. Vet Hum Toxicol 43:218-219

10. Bizovi KE, Aks SE, Paloucek F et al (1996) Late increase in acetaminophen concentration after overdose of Tylenol extended relief. Ann Emerg Med 28(5):549-551

11. Smith SW, Howland MA, Hoffman RS, Nelson LS (2008) Acetaminophen overdose with altered acetaminophen pharmacokinetics and hepatotoxicity associated with premature cessation of intravenous N-acetylcysteine therapy. Ann Pharmacother 42(9): 1333-1339

12. Ferguson KL, Chan GM, Lee C, Greller HA, Su M (2007) Delayed hepatotoxicity from combined acetaminophen and diphenhydramine despite 21-hour intravenous $\mathrm{N}$-acetylcysteine. Clin Toxicol 45(6):6

13. Chan BS, Graudins A, Chiew A (2008) Acetaminophen poisoning with a difference. Clin Toxicol 46(7):601-602

14. Stolbach AI, Hoffman RS, Howland MA, Nelson LS (2007) Very late second peak in acetaminophen concentration following Tylenol extended relief overdose. Clin Toxicol 45:350

15. Schwartz EA, Hayes BD, Sarmiento KF (2008) Development of hepatic failure despite use of intravenous acetylcysteine after a massive ingestion of acetaminophen and diphenhydramine. Ann Emerg Med (article in press, November 2008) [cited May 6, 2009]; Available from http://www.annemergmed.com/inpress

16. Kobrinsky NL, Hartfield D, Horner H et al (1996) Treatment of advanced malignancies with high-dose acetaminophen and Nacetylcysteine rescue. Cancer Invest 14:202-210

17. Hendrickson RG, Bizovi KE (2006) Acetaminophen. In: Goldfrank L, Flomenbaum N, Lewin N, Howland MA, Hoffman R, Nelson L (eds) Goldfrank's Toxicologic Emergencies, 8th edn. Appleton and Lange, Stamford

18. Adams BK, Mann MD, Aboo A, Isaacs S, Evans A (2004) Prolonged gastric emptying half-time and gastric hypomotility after drug overdose. Amer J Emerg Med 22(7):548-554

19. Halcomb SE, Sivilotti MLA, Goklaney A, Mullins ME (2005) Pharmacokinetic effects of diphenhydramine or oxycodone in simulated acetaminophen overdose. Acad Emerg Med 12(2):169-172

20. Waring WS, Benhalim S (2008) Serum acetaminophen concentrations after acute overdose are not altered by opioid coingestion. J Toxicol Sci 33(5):549-553

21. Hojer J, Personne M (2008) Endoscopic removal of slow release clomipramine bezoars in two cases of acute poisoning. Clin Toxicol 46(4):317-319

22. Iberti T, Patterson B, Fisher C (1984) Prolonged bromide intoxication resulting from a gastric bezoar. Arch Intern Med 144:402-403 
23. Jenis EH, Payne RJ, Goldbaum LR (1969) Acute meprobamate poisoning: a fatal case following a lucid interval. JAMA 207: 361-365

24. Roberts MS, Magnusson BM, Burzxynski FJ, Weiss M (2002) Enterhepatic circulation: physiological, pharmacokinetic and clinical implications. Clin Pharmacokinet 41:751-790

25. Seigers CP, Rozman K, Klaassen CD (1983) Biliary excretion and enterohepatic circulation of paracetamol in the rat. Xenobiotica 13:591-596

26. Watari N, Iwai M, Kaneniwa N (1983) Pharmacokinetic study of the fate of acetaminophen and its conjugates in rats. J Pharmacokinet Biopharm 11:245-272

27. Christophersen AB, Hoegberg LCG, Kristensen K, Skanning PG, Angelo HR, Christensen HR (2004) The effect of activated charcoal, given as an oral solution, on the elimination half-life of intravenous paracetamol. Clin Toxicol 42(4):561

28. Singer AJ, Carracio TR, Mofenson HC (1995) The temporal profile of increased transaminase levels in patients with acetaminophen-induced liver dysfunction. Ann Emerg Med 26 (1):49-53

29. Spiller HA, Winter ML, Klein-Schwartz W, Bangh SA (2006) Efficacy of activated charcoal administered more than four hours after acetaminophen overdose. J Emerg Med 30(1):1-5

30. Olkkola KT (1985) Effect of charcoal-drug ratio on antidotal efficacy of oral activated charcoal in man. Br J Clin Pharmac 19:767-773

31. Dart RC, Rumack BH (2007) Patient-tailored acetylcysteine administration. Ann Emerg Med 50:280-281 